J Ultrasound Med. 2019 October ; 38(10): 2575-2587. doi:10.1002/jum.14950.

\title{
Pulmonary Capillary Hemorrhage Induced by ARFI Shear Wave Elastography in Ventilated Rats
}

\author{
Douglas L. Miller, PhD, FAIUM ${ }^{1}$, Zhihong Dong, MD ${ }^{1}$, Chunyan Dou, MD ${ }^{1}$, Brandon \\ Patterson, $\mathrm{PhD}^{1}$, Krishnan Raghavendran, $\mathrm{MD}^{2}$ \\ ${ }^{1}$ Department of Radiology, University of Michigan, Ann Arbor, MI. 48109 \\ ${ }^{2}$ Department of Surgery, University of Michigan, Ann Arbor, MI. 48109
}

\begin{abstract}
Objectives: Diagnostic ultrasound (DUS) imaging can induce pulmonary capillary hemorrhage $(\mathrm{PCH})$, possibly related to the ultrasonic radiation pressure arising from reflection at the lung blood-air interfaces. Acoustical radiation force impulse (ARFI) elastography is a relatively new diagnostic ultrasound mode with high energy "push-pulses" used to move tissue and generate shear waves. The objective was to characterize DUS-PCH induced by the ARFI elastography mode for comparison to other previously tested DUS modes.
\end{abstract}

Methods: PCH induction was examined for ARFI elastography frames with 5.7 MHz pushpulses (Acuson S3000, Siemens Medical Solutions USA, Mountain View, CA, USA), which had a derated peak rarefactional pressure amplitude (PRPA) of 2.6 MPa. Groups of rats with tracheal tube placement had no ventilation (spontaneous breathing), intermittent positive pressure ventilation (IPPV), or IPPV plus $8 \mathrm{~cm} \mathrm{H}_{2} \mathrm{O}$ of positive end expiratory pressure (PEEP). Exposure was to 1 or 20 manually triggered image frame acquisitions. $\mathrm{PCH}$ area was measured on the lung surface.

Results: All 20 frame exposure groups, and even the single frame group, had significant $\mathrm{PCH}$ relative to shams. One frame exposures produced significantly less $\mathrm{PCH}(\mathrm{p}=0.002)$ than 20 frame exposure in rats with tracheal tube only (spontaneous breathing). The PEEP inhibited the $\mathrm{PCH}$ and produced about half the PCH area induced by IPPV without PEEP $(\mathrm{p}=0.014)$.

Conclusions: The PCH results were comparable to those from a previous study using B mode or color Doppler mode exposure for 5 min; however, these modes delivered many more pulses for continuous imaging frames, suggesting that the ARFI elastography frames were individually much more effective.

\section{Keywords}

Pulmonary diagnostic ultrasound; Mechanical index; Comet-tail artifact; Mechanical ventilation; Ultrasound elastography; Diagnostic ultrasound safety

Corresponding author: Douglas L. Miller, 3240A Medical Sciences Building I, University of Michigan Health System, 1301 Catherine Street, Ann Arbor MI 48109-5667, Tel: (734) 647-3344, FAX: (734) 764-8541, douglm@umich.edu. 


\section{Introduction}

Diagnostic ultrasound (DUS) imaging of post-natal mammalian lung can induce pulmonary capillary hemorrhage (PCH) [1]. This phenomenon was discovered by Child et al. [2] using pulsed ultrasound, and has received attention in research designed to quantify ultrasound exposure-response trends and to assess the potential safety issue for patients. Authoritative reviews indicate that DUS-PCH has been observed in different mammalian species, confirmed in different laboratories, and presents a potential risk factor for diagnostic ultrasound $[3,4]$. Direct pulmonary DUS examination is performed in various clinical settings for diagnosis of pneumonia, pulmonary edema, embolism, pneumothorax, atelectasis, diffuse parenchymal disease, respiratory distress syndrome, and lung cancer [58]. The lung may also receive incidental exposure, such as during echocardiography [4]. The use of portable ultrasound machines allows DUS to be performed by the physician at the point of care for routine monitoring [9-11]. This widespread use of pulmonary DUS and the apparent safety issue motivates research to define the possible risks of $\mathrm{PCH}$ for patients and generate suitable safety guidance.

Our work using diagnostic ultrasound systems (early work utilized single element laboratory systems) in rats has provided results for ultrasound exposure from clinical probes and imaging [1]. Interestingly the DUS machines causing PCH also display its occurrence in the B-mode images as growing comet-tail artifacts (also known as B-lines) [1]. Different modes of ultrasound were tested and found to have different $\mathrm{PCH}$ exposure-response characteristics [12]. A GE Vivid 7 Dimension ultrasound machine with 10L linear array probe was used at 6.6 MHz. At the higher power levels, $\mathrm{PCH}$ from B mode or Color Angio mode Doppler imaging produced a band of $\mathrm{PCH}$ corresponding to the scan plane, while fixed beam M mode or pulsed Doppler mode produced an isolated spot of PCH. Pulse peak rarefactional pressure amplitude (PRPA) thresholds were 1.5 MPa for B mode, 1.1 MPa for Angio Doppler mode, 1.1 MPa for M mode and 0.6 MPa for pulsed Doppler mode. The pulsed Doppler mode had relatively long pulses (1130 ns versus $269 \mathrm{~ns}$ for M mode) and relatively high exposure duty cycle $\left(7.7 \cdot 10^{-3}\right.$ versus $0.27 \cdot 10^{-3}$ for $\mathrm{M}$ mode), which may explain its relatively low threshold.

The physical mechanism for PCH induced by pulsed ultrasound has not been clearly established [13]. DUS-PCH has thresholds that are well defined for a given set of conditions, but vary for different specific situations. Thresholds for $\mathrm{PCH}$ do not have a clear frequency dependence [14], which suggests that a frequency independent mechanism, such as the ultrasonic radiation pressure on the lung surface $\left(\mathrm{P}_{\mathrm{urs}}\right)$, may be important for induction of PCH [13]. High intensity focused ultrasound can perturb a liquid surface and produce fountains and atomization, which might also play a role in DUS-PCH [15-17]. PCH induction depends on physical exposure parameters, including pulse duration, pulse repetition frequency and exposure duration in addition to PRPA [4]. In addition, DUS-PCH depends on physiological conditions; for example, $\mathrm{PCH}$ induction in rats with anesthesia using only ketamine is increased substantially when xylazine is used together with ketamine for anesthesia [18]. 
DUS-PCH also was strongly influenced by intermittent positive pressure ventilation (IPPV) [19]. In addition to the IPPV, which simulates normal respiration volume and rate, positive end expiratory pressure (PEEP) was applied. By maintaining positive pressure, PEEP tends to compress the capillaries, reduce trans-capillary pressure, and reduce capillary perfusion [20]. PEEP is often used clinically at a low value of $4-5 \mathrm{~cm} \mathrm{H}_{2} \mathrm{O}$ to maintain oxygenation and prevent alveolar collapse. Higher PEEP can be used to recruit alveoli and minimize pulmonary edema [21]. Intubated rats received normal positive pressure ventilation (IPPV) with zero end expiratory pressure, IPPV with $+4 \mathrm{~cm} \mathrm{H}_{2} \mathrm{O}$ positive end expiratory pressure (PEEP) or IPPV with $-4 \mathrm{~cm} \mathrm{H}_{2} \mathrm{O}$ negative end expiratory pressure (NEEP)[19]. A Philips HDI 5000 ultrasound machine was used with CL15-7 Compact Linear Array probe at 7.6 MHz. The use of NEEP enhanced PCH and PEEP virtually eliminated PCH compared to normal IPPV. Threshold PRPAs were 1.3 MPa for IPPV, 2.1 MPa for IPPV with PEEP and 1.0 MPa for IPPV with NEEP. The $\pm 4 \mathrm{~cm} \mathrm{H}_{2} \mathrm{O}$ variation in pressure was small (e. g. atmospheric pressures is $\sim 1,000 \mathrm{~cm} \mathrm{H}_{2} \mathrm{O}$ ), but comparable in magnitude to the expected $\mathrm{P}_{\mathrm{URS}}$. Note that the application of PEEP was a test for the importance of very small pressures on the gas side of the pulmonary blood-air barrier, which oppose the small ultrasonic radiation surface pressure, and not a test for the cavitation mechanism of bioeffects. Ultrasonic cavitation does not appear to be responsible for DUS-PCH [13], and tests of the role of cavitation in bioeffects, for example in lung [22] or focused ultrasound atomization [23], require much higher static pressures $>1 \mathrm{MPa}\left(>10,000 \mathrm{~cm} \mathrm{H}_{2} \mathrm{O}\right)$.

DUS elastography using acoustic radiation force impulses (ARFI) to probe tissue has been developed to provide information on tissue stiffness and this new DUS mode presents a substantially different ultrasound exposure from the other imaging modes noted above. Several different diagnostic ultrasound elastography methods are available [24, 25] and ARFI elastography is used clinically for assessment of breast [26], liver [27], and other tissues. For ARFI elastography, relatively long ultrasound pulses (often called "pushpulses") are used to cause tissue in the ultrasound beam to move with displacements that can exceed $10 \mu \mathrm{m}[28,29]$. The displacements can be measured by evaluation of tissue echoes, or by ultrasonic measurement of the shear waves generated by the impulsive motion. The shear wave method allows quantitative measurements of shear wave velocity and tissue elasticity estimates.

The use of push-pulse methods in DUS elastography might be considered a qualitatively different type of ultrasound exposure from conventional DUS, and possible specific bioeffects that could be associated specifically with ARFI elastography have received some consideration. The potential for excessive ultrasonic heating has been of interest due to the long duration ARFI elastography pulses [30-32]. In soft tissue, the temperature elevations for single push-pulses appear to be a few degrees $\mathrm{C}$, but elevations in bone could be much higher, and bone should be avoided in ARFI elastography. The temperature elevations created by repeated ARFI image frames potentially can build to values that are of concern, and therefore inter-frame intervals should be sufficient to avoid excessive heat buildup [32].

Takayama et al. [33] reported PCH in a rabbit exposed to ARFI elastography-like pulses from a custom made transducer. The $2.5 \mathrm{MHz}$ pulses were $10 \mathrm{~ms}$ in duration, and repeated at 
$5 \mathrm{~s}$ intervals for $150 \mathrm{~s}$. The $\mathrm{PCH}$ area was visible on the surface and was observed in histological sections to be $20-170 \mu \mathrm{m}$ below the surface.

The dependence of $\mathrm{PCH}$ induced by pulsed ultrasound on pulse duration was investigated by Child et al. [2]. For $10 \mu$ s pulses, increasing the pulse repetition period (PRP) from $1 \mathrm{~ms}$ to $10 \mathrm{~ms}$ had no effect on the PCH threshold in mice, while decreasing the pulse duration to 1 $\mu$ s with $10 \mathrm{~ms}$ pulse repetition period increased the threshold. A trend of decreasing thresholds for increasing pulse durations from $1.3 \mu$ s to $11.6 \mu$ s was also found by O'Brien et al. [34]. The thresholds also depend on overall exposure duration for laboratory pulsed [35] and diagnostic scanned ultrasound [36]. The pulsed Doppler mode of diagnostic ultrasound was substantially more effective than $\mathrm{M}$ mode, as noted above.

The ARFI elastography utilizes scanned, relatively long duration push-pulses, plus repeated shear-wave interrogation pulses, and might be expected to have a greater PCH impact than the other modes. This present study was undertaken to assess PCH occurrence in rats due to single and multiple ARFI elastography frames from a clinical ultrasound machine. The $\mathrm{PCH}$ associated with the push-pulses was specifically examined by reducing the output of the other pulses to $5 \%$ of maximum. In addition, IPPV was used with a PEEP of $8 \mathrm{~cm} \mathrm{H}_{2} \mathrm{O}$ for comparison to the previous study of the influence of IPPV with PEEP. The goals were to characterize DUS-PCH from the ARFI elastography mode for comparison to other previously tested DUS modes and to assess the relative reduction in $\mathrm{PCH}$ due to added PEEP.

\section{Materials and Methods}

\section{Animal preparation}

All in vivo animal procedures were conducted with the approval and guidance of the Institutional Animal Care and Use Committee (IACUC) of the University of Michigan. Female rats (Sprague Dawley, Charles River, Wilmington, MA, USA) were used for this study, as described previously [1]. Rats were anesthetized by intraperitoneal injection of 91 $\mathrm{mg} / \mathrm{kg}$ ketamine (Zetamine ${ }^{\mathrm{TM}}$ ketamine hydrochloride injection, MWI, Boise, ID, USA) plus $9 \mathrm{mg} / \mathrm{kg}$ IP xylazine (XylaMed ${ }^{\mathrm{TM}}$ xylazine injection, MWI, Boise, ID, USA), which is the recommended anesthetic for rats. The right thorax was shaved and depilated for ultrasound transmission. A tracheostomy was performed and the trachea was intubated with a plastic tube ( $2.2 \mathrm{~mm}$ OD, $1.3 \mathrm{~mm}$ ID) with Luer lock fitting. For ultrasound exposure, the rats were mounted on a holding board in dorsal recumbent position, and the board was mounted vertically in a $38{ }^{\circ} \mathrm{C}$ degassed water bath. This allowed for accurate ultrasound imaging and exposures of the right lung with ultrasound probes also mounted in the water bath.

The tracheal tube was stabilized on the mounting stand for connection to a ventilator as needed. The rats were able to breathe spontaneously through the tracheostomy tube. For normal intermittent positive pressure ventilation (IPPV), a rodent ventilator (TOPO Dual Mode ventilator, Kent Scientific, Torrington, CT, USA) was connected by a tubing TEE. The normal ventilator setting was a respiration rate of 75 breaths per minute with $25 \%$ positive inspiration at $15 \mathrm{~cm} \mathrm{H}_{2} \mathrm{O}$ during the ventilation cycle, as recommended for rats in the operator's manual. To generate $8 \mathrm{~cm} \mathrm{H}_{2} \mathrm{O}$ positive end expiratory pressure (PEEP), a bottle 
of water containing $8 \mathrm{~cm}$ of water was attached to the expiration port of the ventilator. The ventilation pressure and PEEP were confirmed with a low pressure gauge ( \pm 5 PSI Traceable, Fisher Scientific Co. Houston TX USA).

\section{Ultrasound}

An Acuson S3000 ultrasound machine with 9L4 Multi-D matrix probe (Siemens Medial Solutions USA, Mountain View CA, USA) was used in the Virtual Touch IQ mode. The probe was mounted in the water bath and B mode imaging at 5\% power was used to aim through an intercostal space at the right cranial or medial lobe of the rat lung. Scanning used $3 \mathrm{~cm}$ image depth, $3.66 \mathrm{~cm}$ image width, $2 \mathrm{~cm}$ focal depth, and the MultiHz $9 \mathrm{MHz}$ setting. For Virtual Touch IQ elastography, the elastography image box was expanded to the maximum size of $2.55 \mathrm{~cm}$ deep by $3.66 \mathrm{~cm}$ wide, starting at $0.2 \mathrm{~cm}$ depth. For exposure, the lung surface image was adjusted to place the closest point at a $1.4 \mathrm{~cm}$ image depth. The power setting of 5\% power, which gave an on-screen MI of 0.3 (below the PCH threshold for B mode), was retained for exposure so that only the effects associated with the ARFI elastography push-pulses would occur. The output for the ARFI push-pulses could not be reduced, which prevented a determination of an exposure threshold for $\mathrm{PCH}$ using this mode. The system enforced a cool down interval of $5 \mathrm{~s}$ after an ARFI frame during which a frame update could not be triggered. The exposure consisted of 1 or 20 manually initiated frames at intervals of about $15-18 \mathrm{~s}$ (including the cooling period, reset time and the time needed to save images). The elastography image was color mapped for shear wave velocity, and had a scale of $0.5 \mathrm{~m} / \mathrm{s}$ to $6.5 \mathrm{~m} / \mathrm{s}$.

The ultrasound pulse parameters were measured in the water bath using a calibrated hydrophone with a $0.2 \mathrm{~mm}$ sensitive spot (model HGL-0200, Onda Corp., Sunnyvale, CA). The hydrophone was visible in the image and was placed at the $1.4 \mathrm{~cm}$ depth corresponding to the surface of the lung during exposures, and moved along the scan plane to find the position of maximum PRPA of the ARFI pulses. Pulse waveforms were digitized on an oscilloscope and transferred to a computer for determination of pulse characterization parameters. The ARFI elastography involves two types of pulses, push-pulses and sets of Bmode like pulses, which interrogate shear wave motion and provide the background grayscale image. An ARFI elastography pulse sequence is shown in Fig. 1a and was about $1.1 \mathrm{~s}$ in duration. This complex sequence shows 92 ARFI push-pulses spaced about $11.8 \mathrm{~ms}$ apart, which have different amplitudes due to the beam scanning or focus depth differences. The four equal maximal push-pulses were recorded when the scanned beam was aimed directly at the hydrophone. The pulses were grouped into 4 similar sets of scans spaced 286 ms apart. The maximal push-pulses of interest for this study were pairs of $5.7 \mathrm{MHz}$ continuous wave bursts $61 \mu \mathrm{s}$ in duration and spaced $49 \mu$ s apart, as shown in Fig. 1b. The $-6 \mathrm{~dB}$ beam width of the push pulses was $3 \mathrm{~mm}$. The water values of ultrasound pressure amplitudes were derated by $1.2 \mathrm{~dB} / \mathrm{cm} / \mathrm{MHz}$, which was equal to $-3.4 \mathrm{~dB}$ for the chest wall thickness of about $0.5 \mathrm{~cm}$, to obtain in situ values [14]. The derated push-pulse peak compressional pressure amplitude, PRPA and mean pressure amplitude were 5.0 MPa, 2.6 $\mathrm{MPa}$ and $3.8 \mathrm{MPa}$, respectively. The derated PRPA was used to calculate the in situ MI $\left(\mathrm{MI}_{\mathrm{IS}}\right)$ as the PRPA divided by the square root of $5.7 \mathrm{MHz}$, which was equal to 1.1. The derated pulse waveform was used to calculate the spatial peak pulse average intensity 
( $\left.\mathrm{I}_{\text {SPPA }}\right)$, which was $338 \mathrm{~W} / \mathrm{cm}^{2}$. In addition, the ultrasonic radiation surface pressure $\left(\mathrm{P}_{\mathrm{URS}}\right)$ was calculated from the derated ISPPA intensity, as described in Miller [13], and was $45 \mathrm{~cm}$ $\mathrm{H}_{2} \mathrm{O}$ during the maximal push-pulses.

\section{Measured endpoints}

The rats weighed an average of $247 \mathrm{~g}$ (14 Std. Dev.). Heart rate and $\mathrm{SpO}_{2}$ were measured with a pulse oximeter probe (SurgiVet V3395 TPR, Smiths Medical Inc. St Paul, MN USA) on a front paw before the scanning procedure and were 264 (36 Std. Dev.) beats per min, and 76.4 (8.0 Std. Dev) percent, respectively. PCH-related endpoints included the percentage of the bright-line image of the lung surface, which was involved with comet-tail artifacts (CTAs) 5 min post exposure. The rat was then euthanized, the trachea was tied off, and the lungs were removed. The right lobes, which were the target of the imaging, were then examined and photographed using a stereomicroscope (Leica S6D, Leica Microsystems Inc. Buffalo Grove, IL USA). Digital photographs (Moticam 580, Motic, Richmond, BC, Canada) of the lungs were used to measure the approximate area of the region of PCH on the lung surface by manual outline of the region, using image analysis with Motic Image Plus 2.0 ML software. The lungs were then fixed in neutral buffered formalin and used to measure the depth of the larger PCH regions in order to obtain estimates of the $\mathrm{PCH}$ volume. Depths were measured in $2 \mathrm{~mm}$ intervals by slicing $2 \mathrm{~mm}$-thick sections (the smallest thickness reproducibly attainable by hand sectioning) and measuring under the stereomicroscope. The mean depth of a $\mathrm{PCH}$ volume was then multiplied by the $\mathrm{PCH}$ area measured in fresh tissue, as described previously [36].

\section{Experimental plan and statistics}

The ARFI push-pulses had a fixed output and were triggered by the "update" key on the machine, which triggered generation of a new elastography image frame. Tracheal tubes were used with spontaneous breathing (no IPPV) in two groups of 6 rats. One of these groups was tested with single frame exposure and the other group was tested with 20 frames of exposure, which took about 5-6 min to complete. One group of 6 rats had IPPV with 20 frames of exposure. IPPV plus $8 \mathrm{~cm} \mathrm{H}_{2} \mathrm{O}$ PEEP was used for 6 rats with sham exposure (aim only) and 7 rats with 20 frame exposures. Statistical significance of each results was determined using the simple t-test of the means for exposed versus shams with significance assumed for $\mathrm{p}<0.05$. Alternatively, results compared as the proportion of rats in a group with $\mathrm{PCH}$ occurrence using the $\mathrm{Z}$ test with Yates correction (i. e., occurrence in 5 of 6 rats was significant) gave the same significance determinations.

\section{Results}

The B mode images of an intubated rat without IPPV saved before and after 20 frames of ARFI elastography exposure are shown in Fig. 2 together with a photograph of the injured lung. The CTAs fill the exposed lung surface image. The lung photograph has all three right lung lobes in view, each of which has a PCH area. The PCH areas all occurred in the scan plane in vivo, but the lobes have moved relative to each other after removal. A similar presentation in Fig. 3 shows numerous PCH spots on the medial lobe produced by one frame 
of ARFI elastography. For this single frame exposure, the CTAs in the B mode image taken after exposure are visible as several small artifacts.

Results for a rat with IPPV and 20 frames of ARFI elastography are shown in Fig. 4. This lung had a large PCH impact similar to that without IPPV (Fig. 2) and the after-exposure B mode image shows CTAs across the entire lung surface image. The ARFI image of shear wave velocity did not display any clearly evident changes between the first and last frame, as shown in Fig. 5, corresponding to the before and after B mode images in Fig. 4. For this rat, the B mode images for each of the 20 ARFI frames presented in Fig. 6 showed a progressive appearance of CTAs.

When PEEP was applied with the IPPV, the PCH effect was often substantial but not as extensive as that found without PEEP, as shown in Fig. 7. The B mode image shows a limited width of CTAs, and the lung photograph has a single large $\mathrm{PCH}$ area within part of the scan plane region of the medial lobe. A noteworthy feature of this lesion was that, although much of the lung appeared to be unaffected, the PCH in the affected area penetrated completely through the lobe, as for the exposures without PEEP.

The measured endpoint results are presented in Table 1. The widths of comet-tail artifacts (CTAs), which closely tracked the width of PCH on the lungs, were measured as a percentage of the width (which averaged $21.1 \mathrm{~mm} \pm 2.2 \mathrm{~mm}$ ) of the bright line surface image. The percentage of the surface image showing CTAs was essentially $100 \%$ for the 20 frame Tube-Only and IPPV conditions, but reduced to $56 \%$ ( $\mathrm{p}=0.001$ relative to sham) for IPPV plus PEEP. The CTAs were only $6 \%$ (not significantly different from sham) for the tube-only group exposed to one elastography frame. Figure 8 compares the $\mathrm{PCH}$ area determined for each test group. The exposed groups, including the single frame exposure, had statistically significant PCH area relative to shams. The tube-only and IPPV groups with 20 frame exposure were not significantly different. The single frame exposure gave significantly less effect than the 20 frame exposure with tube only ( $\mathrm{p}=0.015)$. The use of 8 $\mathrm{cm} \mathrm{H}_{2} \mathrm{O}$ PEEP reduced the PCH to about half of the result for the IPPV group $(\mathrm{p}<0.001)$.

The PCH depth measurements in fixed tissue were partly determined by the thickness of the lobes, because many PCH volumes passed entirely through the lobe. The mean depth noted was $1.1 \pm 0.6 \mathrm{~mm}$ in the cranial lobe, $3.7 \pm 0.7$ in the medial lobe and $1.5 \pm 0.6$ in the caudal lobe. The mean total PCH volumes in all three lobes are listed in Table 1. The PCH volume for IPPV plus PEEP was significantly less than that for the tube only condition $(\mathrm{p}=0.017)$ and the IPPV condition $(\mathrm{p}=0.031)$.

\section{Discussion and Conclusion}

ARFI elastography is a relatively new diagnostic ultrasound mode with exposure pulse sequences distinctly different from other diagnostic ultrasound modes. This mode was tested to specifically assess the $\mathrm{PCH}$ from the $5.7 \mathrm{MHz}$ push-pulses, that consisted of two $62 \mu \mathrm{s}$ pulses $49 \mu$ s apart (Fig. 1b), repeated at $11.8 \mathrm{~ms}$ interval with a derated PRPA of 2.6 MPa. The PCH produced by 20 ARFI elastography frames repeated manually at intervals of about $18 \mathrm{~s}$, was substantial, filling the scan plane with $\mathrm{PCH}$ areas of 36.9 and $34.4 \mathrm{~mm}^{2}$, for the 
Tube only and IPPV modes, respectively. Unfortunately, the output was fixed, so that exposure response thresholds could not be determined for this DUS mode. This maximal PCH impact was about the same as for maximal application of other diagnostic ultrasound modes. For example, $6.6 \mathrm{MHz} \mathrm{B}$ mode and Angio pulsed Doppler imaging modes were previously tested and had pulse durations of $268 \mathrm{~ns}$ and $319 \mathrm{~ns}$ with 60 and 17.5 frames per second (fps), respectively [12]. These B and Angio Doppler modes produced maximal PCH areas of $45 \mathrm{~mm}^{2}$ and $55 \mathrm{~mm}^{2}$ for derated PRPAs of 3.3 and $2.7 \mathrm{MPa}$, respectively. For $5 \mathrm{~min}$ exposures, however, these modes delivered many more frames (18,000 for B mode and 5250 for Angio Doppler mode), suggesting that the ARFI elastography frames were individually much more effective. Indeed, exposure from one ARFI elastography frame produced a clear and statistically significant $\mathrm{PCH}$ result.

Ventilation with PEEP was used in order to determine whether the $\mathrm{PCH}$ would be greatly inhibited, as it was for B mode imaging [19]. The PCH was inhibited, but the PCH area observed was still about half that of IPPV without PEEP. The occurrence was variable and was substantial in some rats (Fig. 7). For B mode ultrasound the $\mathrm{PCH}$ was essentially eliminated by only $4 \mathrm{~cm} \mathrm{H}_{2} \mathrm{O}$, again suggesting that the ARFI push-pulses were more effective than the $\mathrm{B}$ mode pulses. Regarding the ultrasound radiation surface pressure mechanism, the maximum $\mathrm{P}_{\text {URS }}$ was $22.7 \mathrm{~cm} \mathrm{H}_{2} \mathrm{O}$ in the previous study for an ISPPA 168 W/ $/ \mathrm{cm}^{2}$ compared to $45 \mathrm{~cm} \mathrm{H}_{2} \mathrm{O}$ for $338 \mathrm{~W} / \mathrm{cm}^{2}$ in this study. A PEEP of $8 \mathrm{~cm} \mathrm{H}_{2} \mathrm{O}$ was used in this study compared to $4 \mathrm{~cm} \mathrm{H}_{2} \mathrm{O}$ in the $\mathrm{B}$ mode study [19], because of the expected higher $\mathrm{P}_{\mathrm{URS}}$ for ARFI elastography. Given the different pulse durations and frame rates, the exact implications for this hypothetical PCH mechanism are not clear.

A better understanding of the pulmonary bioeffects potential of diagnostic ultrasound elastography is needed for clinical safety assessment. Investigation of PCH induction by an Aixplorer elastography machine (SuperSonic Imagine, Aix en Provence, FR), which incorporates a different push-pulse strategy with $1 \mathrm{fps}$ and output power variation suitable for exposure-response experiments, should establish the threshold for induction of $\mathrm{PCH}$ by push-pulses designed to generate shear waves. The diagnostic value of DUS elastography may be enhanced by conditionally increasing pulse amplitudes, and the use of MI values of up to 4 have been suggested for this purpose [37]. The higher pulse amplitude would represent greatly increased exposure relative to this study with $\mathrm{MI}_{\mathrm{IS}}=1.1$. Further research is needed to clarify PCH mechanisms. High intensity focused ultrasound directed upward at a liquid surface can produce fountains and atomization, phenomena that can be responsible for tissue fragmentation and might be involved in PCH [15-17,23]. We have found that present push pulses (limited to DUS MI<1.9) can produce fountains and atomization at a water or blood air interface [38]. Study of the fountain and atomization phenomena with different DUS modes should help to gauge their importance in PCH. This information will establish whether or not DUS elastography represents a qualitatively different exposure regime for PCH risk from othr DUS modes.

\section{Acknowledgments:}

We thank Dr. James Pool, University of Michigan Department of Radiology for facilitating the use of the Acuson S3000 machine. This study was supported by the US National Institutes of Health, National Heart Lung and Blood 
Institute, via grant number HL116434. The information contained herein does not necessarily reflect the position or policy of the US government, and no official endorsement should be inferred.
Abbreviations:
DUS
ARFI
PCH
IPPV
PEEP
NEEP
PRPA
Diagnostic Ultrasound
Acoustic Radiation Force Impulse
Pulmonary Capillary Hemorrhage
Intermittent Positive Pressure Ventilation
Positive End Expiratory Pressure
Negative End Expiratory Pressure
Peak Rarefactional Pressure Amplitude

\section{References:}

1. Miller DL. Induction of pulmonary hemorrhage in rats during diagnostic ultrasound. Ultrasound Med Biol. 2012;38:1476-1482. [PubMed: 22698500]

2. Child SZ, Hart man CL, Schery LA, Carstensen EL. Lung damage from exposure to pulsed ultrasound. Ultrasound Med Biol. 1990;16:817-25. [PubMed: 2095012]

3. American Institute of Ultrasound in Medicine [no authors listed]. Section 4--bioeffects in tissues with gas bodies. J Ultrasound Med. 2000;19:97-108, 154-68. [PubMed: 10680616]

4. Church CC, Carstensen EL, Nyborg WL, Carson PL, Frizzell LA, Bailey MR. The risk of exposure to diagnostic ultrasound in postnatal subjects: nonthermal mechanisms. J Ultrasound Med. 2008;27:565-92. [PubMed: 18359909]

5. Sartori S, Tombesi P. Emerging roles for transthoracic ultrasonography in pleuropulmonary pathology. World J Radiol. 2010;2:83-90. [PubMed: 21160921]

6. Volpicelli G Lung sonography. J Ultrasound Med. 2013; 32:165-171. [PubMed: 23269722]

7. Lichtenstein D Lung ultrasound in the critically ill. Curr Opin Crit Care. 2014;20:315-322. [PubMed: 24758984]

8. Dietrich CF, Goudie A, Chiorean L, Cui XW, Gilja OH, Dong Y, Abramowicz JS, Vinayak S, Westerway SC, Nolsøe CP, Chou YH, Blaivas M. Point of care ultrasound: a WFUMB position paper. Ultrasound Med Biol. 2017;43:49-58. [PubMed: 27472989]

9. Ahmad S, Eisen LA. Lung ultrasound: the basics In Lumb P, Karakitsos D eds. Critical Care Ultrasound. Philadelphia: Elsevier, 2015 pp 105-137.

10. Irwin Z, Cook JO. Advances in point-of-care thoracic ultrasound. Emerg Med Clin North Am. 2016;34:151-157. [PubMed: 26614246]

11. Sekiguchi H Tools of the trade: point-of-care ultrasonography as a stethoscope. Semin Respir Crit Care Med. 2016;37:68-87. [PubMed: 26844609]

12. Miller DL, Dong Z, Dou C, Raghavendran K. Pulmonary capillary hemorrhage induced by different imaging modes of diagnostic ultrasound. Ultrasound Med Biol. 2018;44:1012-1021. [PubMed: 29428168]

13. Miller DL. Mechanisms for induction of pulmonary capillary hemorrhage by diagnostic ultrasound: review and consideration of acoustical radiation surface pressure. Ultrasound Med Biol. 2016;42:2743-2757. [PubMed: 27649878]

14. Miller DL, Dou C, Raghavendran K. The dependence of thresholds for pulmonary capillary hemorrhage on diagnostic ultrasound frequency. Ultrasound Med Biol 2015;41:1640-50. [PubMed: 25746909] 
15. Tjan KK, Phillips WRC. On the impulsive generation of drops at the interface of two inviscid fluids Proc. R. Soc. A 2008;464;1125-1140.

16. Tjan KK, Phillips WRC. On impulsively generated inviscid axisymmetric surface jets, waves and drops. Journal of Fluid Mechanics 2007; 576:377-403.

17. Simon JC, Sapozhnikov OA, Khokhlova VA, Wang YN, Crum LA, Bailey MR. Ultrasonic atomization of tissue and its role in tissue fractionation by high intensity focused ultrasound. Phys Med Biol. 2012;57:8061-78. [PubMed: 23159812]

18. Miller DL, Dou C, Raghavendran K. Anesthetic techniques influence the induction of pulmonary capillary hemorrhage during diagnostic ultrasound in rats. J Ultras Med. 2015;34:289-297.

19. Miller DL, Dong Z, Dou C, Raghavendran K. Pulmonary capillary hemorrhage induced by diagnostic ultrasound in ventilated rats. Ultrasound Med Biol. 2018;44:1810-1817. [PubMed: 29779887]

20. Nieman GF, Paskanik AM, Bredenberg CE. Effect of positive end-expiratory pressure on alveolar capillary perfusion. J Thorac Cardiovasc Surg. 1988;95:712-716 [PubMed: 2451091]

21. Wiesen J, Ornstein M, Tonelli AR, Menon V, Ashton RW. State of the evidence: mechanical ventilation with PEEP in patients with cardiogenic shock. Heart. 2013;99:1812-1817 [PubMed: 23539555]

22. O’Brien WD Jr, Frizzell LA, Weigel RM, Zachary J F. Ultrasound-induced lung hemorrhage is not caused by inertial cavitation. J Acoust Soc Am. 2000;108: 1290-1297. [PubMed: 11008829]

23. Simon JC, Sapozhnikov OA, Wang YN, Khokhlova VA, Crum LA, Bailey MR. Investigation into the mechanisms of tissue atomization by high-intensity focused ultrasound. Ultrasound Med Biol. 2015;41:1372-85. [PubMed: 25662182]

24. Doherty JR, Trahey GE, Nightingale KR, Palmeri ML. Acoustic radiation force elasticity imaging in diagnostic ultrasound. IEEE Trans Ultrason Ferroelectr Freq Control. 2013;60:685-701. [PubMed: 23549529]

25. Shiina T, Nightingale KR, Palmeri ML, Hall TJ, Bamber JC, Barr RG, Castera L, Choi BI, Chou YH, Cosgrove D, Dietrich CF, Ding H, Amy D, Farrokh A, Ferraioli G, Filice C, Friedrich-Rust M, Nakashima K, Schafer F, Sporea I, Suzuki S, Wilson S, Kudo M. WFUMB guidelines and recommendations for clinical use of ultrasound elastography: Part 1: basic principles and terminology. Ultrasound Med Biol. 2015;41:1126-47. [PubMed: 25805059]

26. Barr RG, Nakashima K, Amy D, Cosgrove D, Farrokh A, Schafer F, Bamber JC, Castera L, Choi BI, Chou YH, Dietrich CF, Ding H, Ferraioli G, Filice C, Friedrich-Rust M, Hall TJ, Nightingale KR, Palmeri ML, Shiina T, Suzuki S, Sporea I, Wilson S, Kudo M. WFUMB guidelines and recommendations for clinical use of ultrasound elastography: Part 2: breast. Ultrasound Med Biol. 2015;41:1148-60. [PubMed: 25795620]

27. Ferraioli G, Filice C, Castera L, Choi BI, Sporea I, Wilson SR, Cosgrove D, Dietrich CF, Amy D, Bamber JC, Barr R, Chou YH, Ding H, Farrokh A, Friedrich-Rust M, Hall TJ, Nakashima K, Nightingale KR, Palmeri ML, Schafer F, Shiina T, Suzuki S, Kudo M. WFUMB guidelines and recommendations for clinical use of ultrasound elastography: Part 3: liver. Ultrasound Med Biol. 2015;41:1161-79. [PubMed: 25800942]

28. Palmeri ML, Sharma AC, Bouchard RR, Nightingale RW, Nightingale KR. A finite-element method model of soft tissue response to impulsive acoustic radiation force. IEEE Trans Ultrason Ferroelectr Freq Control. 2005;52:1699-712. [PubMed: 16382621]

29. Palmeri ML, Nightingale KR. Acoustic radiation force-based elasticity imaging methods. Interface Focus. 2011;1:553-64. [PubMed: 22419986]

30. Palmeri ML, Nightingale KR. On the thermal effects associated with radiation force imaging of soft tissue. IEEE Trans Ultrason Ferroelectr Freq Control. 2004;51:551-65. [PubMed: 15217233]

31. Palmeri ML, Frinkley KD, Nightingale KR. Experimental studies of the thermal effects associated with radiation force imaging of soft tissue. Ultrason Imaging. 2004;26:100-14. [PubMed: 15344414]

32. Liu Y, Herman BA, Soneson JE, Harris GR. Thermal safety simulations of transient temperature rise during acoustic radiation force-based ultrasound elastography. Ultrasound Med Biol. 2014;40:1001-14. [PubMed: 24548651] 
33. Takayama N, Ishiguro Y, Taniguchi N, Akai K, Sasanuma H, Yasuda Y, Nitta N, Akiyama I. The effect of ultrasound with acoustic radiation force on rabbit lung tissue: a preliminary study. J Med Ultrason (2001). 2016;43:481-5. [PubMed: 27401323]

34. O'Brien WD, Simpson DG, Frizzell LA, Zachary JF. Threshold estimates and superthreshold behavior of ultrasound-induced lung hemorrhage in adult rats: role of pulse duration. Ultrasound Med Biol. 2003;29:1625-34. [PubMed: 14654157]

35. Miller DL, Dou C, Raghavendran K. Pulmonary capillary hemorrhage induced by fixed-beam pulsed ultrasound. Ultrasound Med Biol. 2015;41:2212-9. [PubMed: 25933710]

36. Miller DL, Dong Z, Dou C, Raghavendran K. Influence of scan duration on pulmonary capillary hemorrhage induced by diagnostic ultrasound. Ultrasound Med Biol. 2016;42:1942-50. [PubMed: 27117631]

37. Nightingale KR, Church CC, Harris G, Wear KA, Bailey MR, Carson PL, Jiang H, Sandstrom KL, Szabo TL, Ziskin MC. Conditionally increased acoustic pressures in nonfetal diagnostic ultrasound examinations without contrast agents: A preliminary assessment. J Ultrasound Med. 2015;34:1-41.

38. Patterson B, Miller DL. Observation of acoustic fountain generation by diagnostic ultrasound shear wave elastography. J Acoust Soc Am. 2018; 144 (no. 3 pt. 2):1670. 

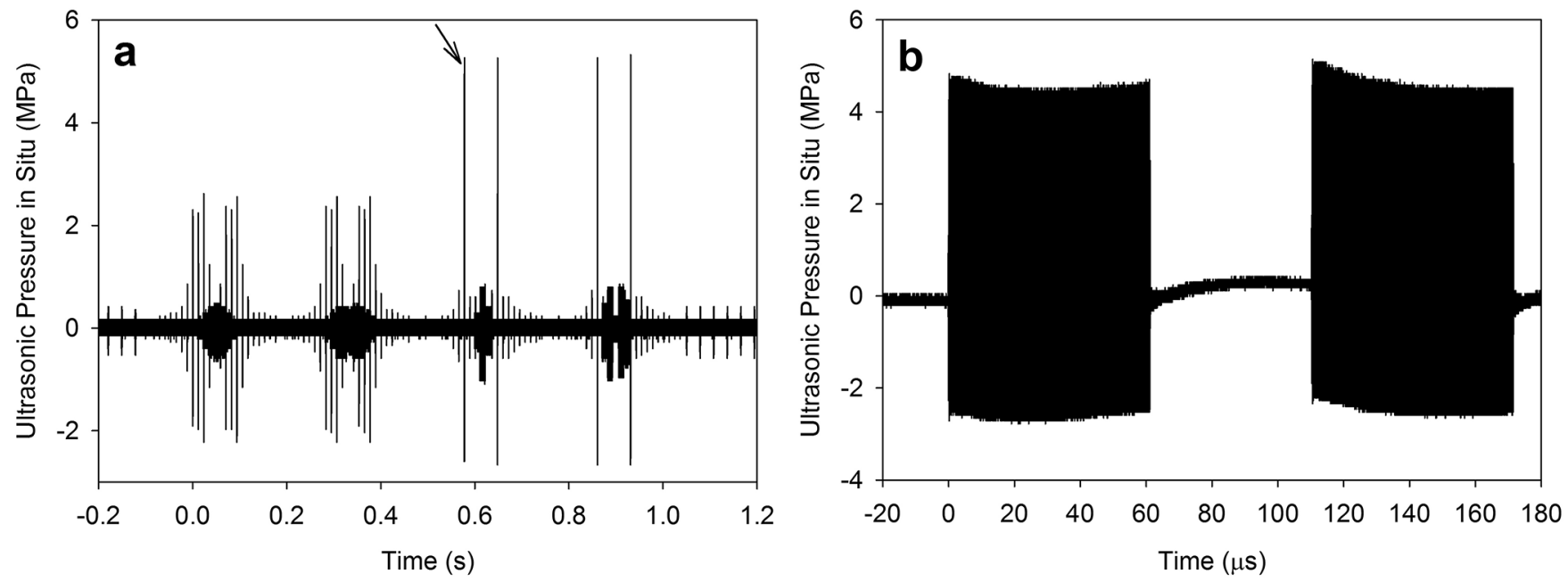

Figure 1.

Plots of the ARFI elastography waveforms from a hydrophone which were digitized on an oscilloscope and derated for attenuation. The hydrophone measures the ultrasonic pressure at its position in the scan plane as a function of time set by a trigger point (zero time in these plots). The waveforms are more complex than a simple B-mode scan, and include B mode image pulses, ARFI image push-pulses and shear wave interrogation pulses. The maximal push-pulse is indicated by the arrow in plot a, which shows the sequence of 4 ARFI image scans (see text), and is displayed in plot $b$ at a higher temporal resolution to show the pair of long pulses which make up the push-pulse. 

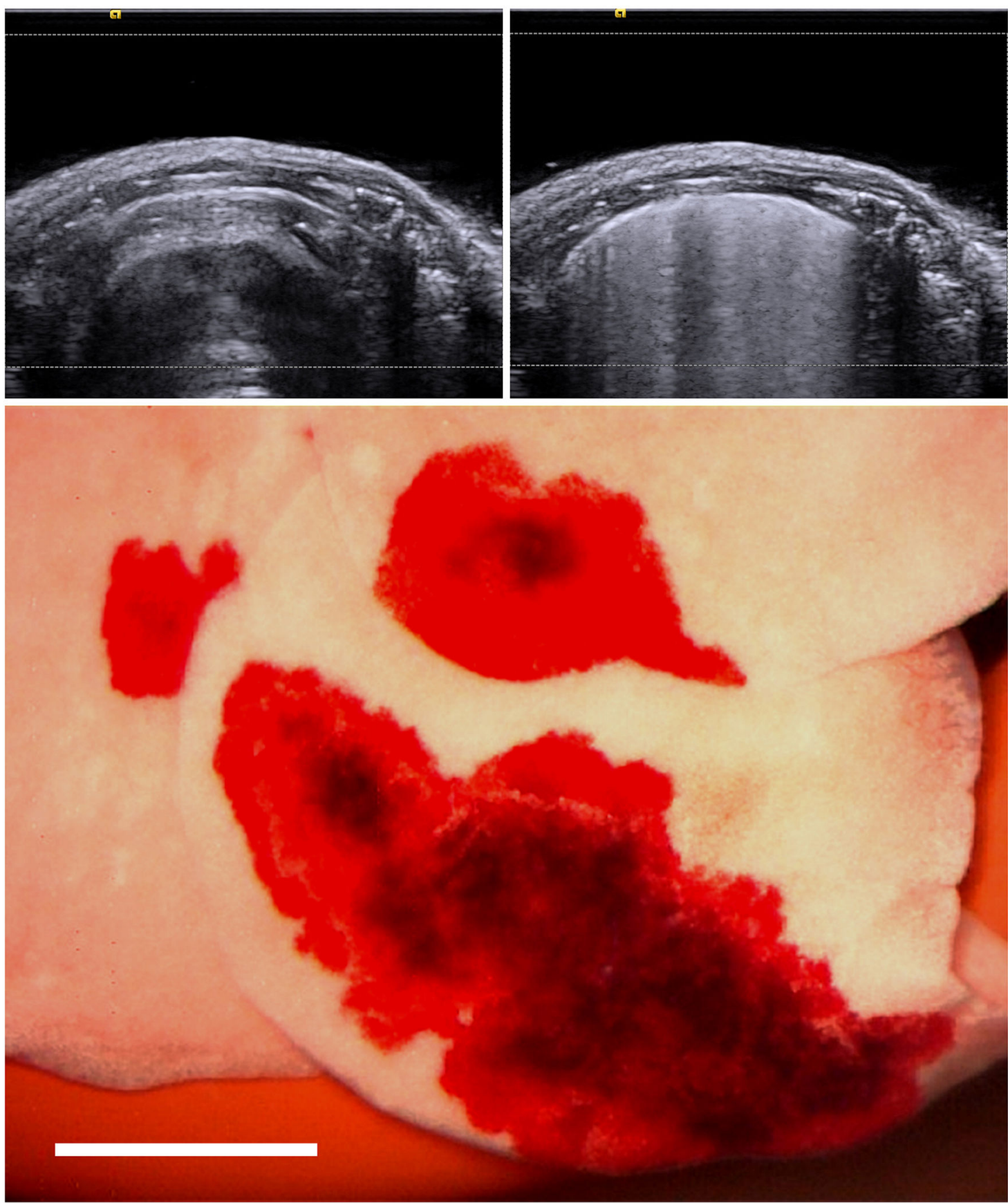

Figure 2.

$\mathrm{B}$ mode images were acquired just before (upper left) and $5 \mathrm{~min}$ after (upper right) 20 ARFI elastography frames for the exposure tests without IPPV (tracheal tube but spontaneous breathing). The after-exposure image displays comet-tail artifacts extending across most of the bright-line surface image seen before exposure. The resulting pulmonary capillary hemorrhage (PCH) areas on the right lung are shown in the bottom photograph (scale bar 5 $\mathrm{mm}$ ). The position of the lung in the sample dish reveals $\mathrm{PCH}$ areas positioned on the cranial (upper right) medial (lower) and caudal lobes (upper left). 

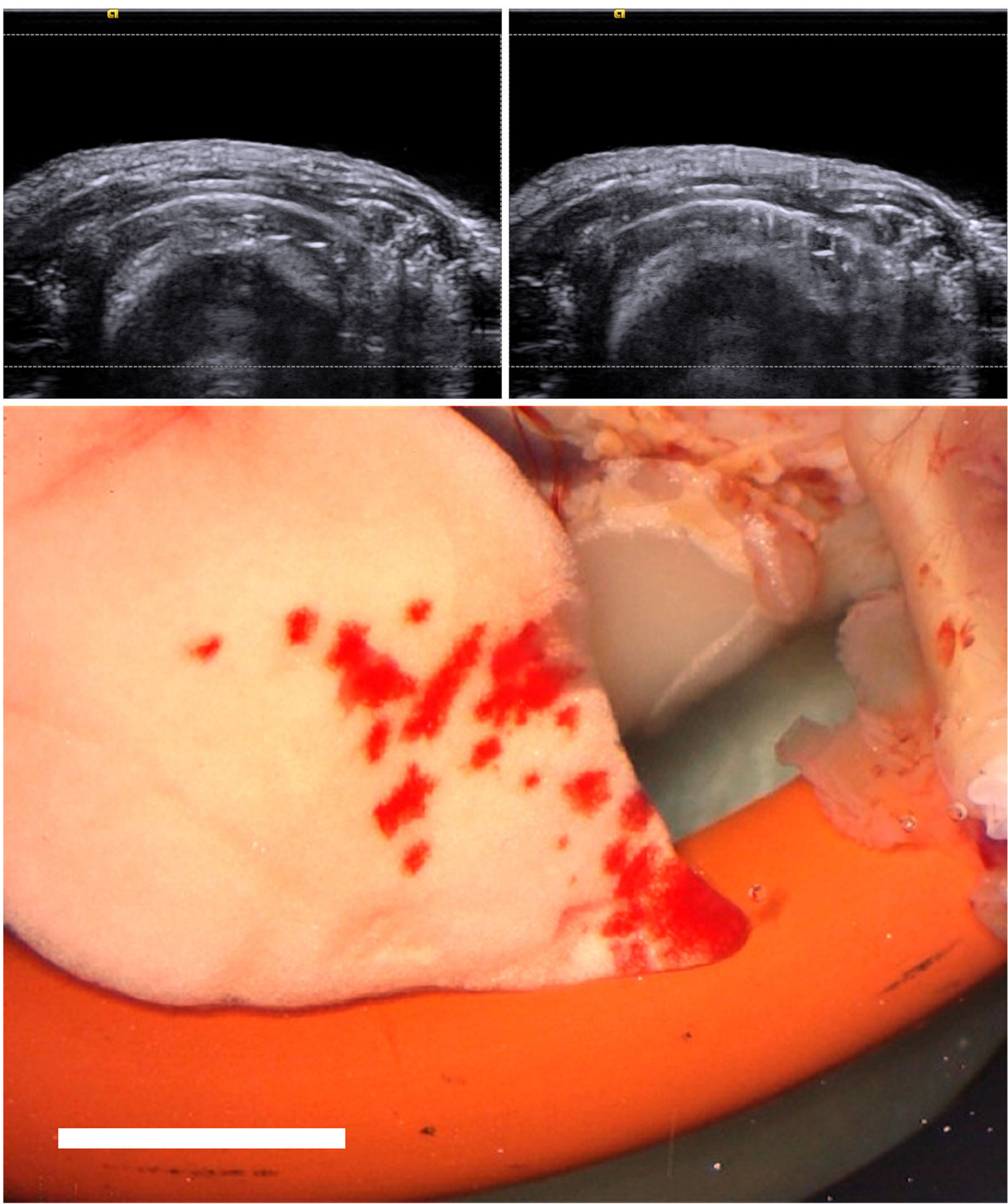

Figure 3.

$\mathrm{B}$ mode images were acquired just before (upper left) and $5 \mathrm{~min}$ after (upper right) 1 ARFI elastography frame with tracheal tube only, presented as in Fig. 2. The after-exposure image displays a few small comet-tail artifacts projecting downward from the center-right region of the lung surface image. The pulmonary capillary hemorrhage areas consist of numerous small spots on the medial lobe (scale bar $5 \mathrm{~mm}$ ). 

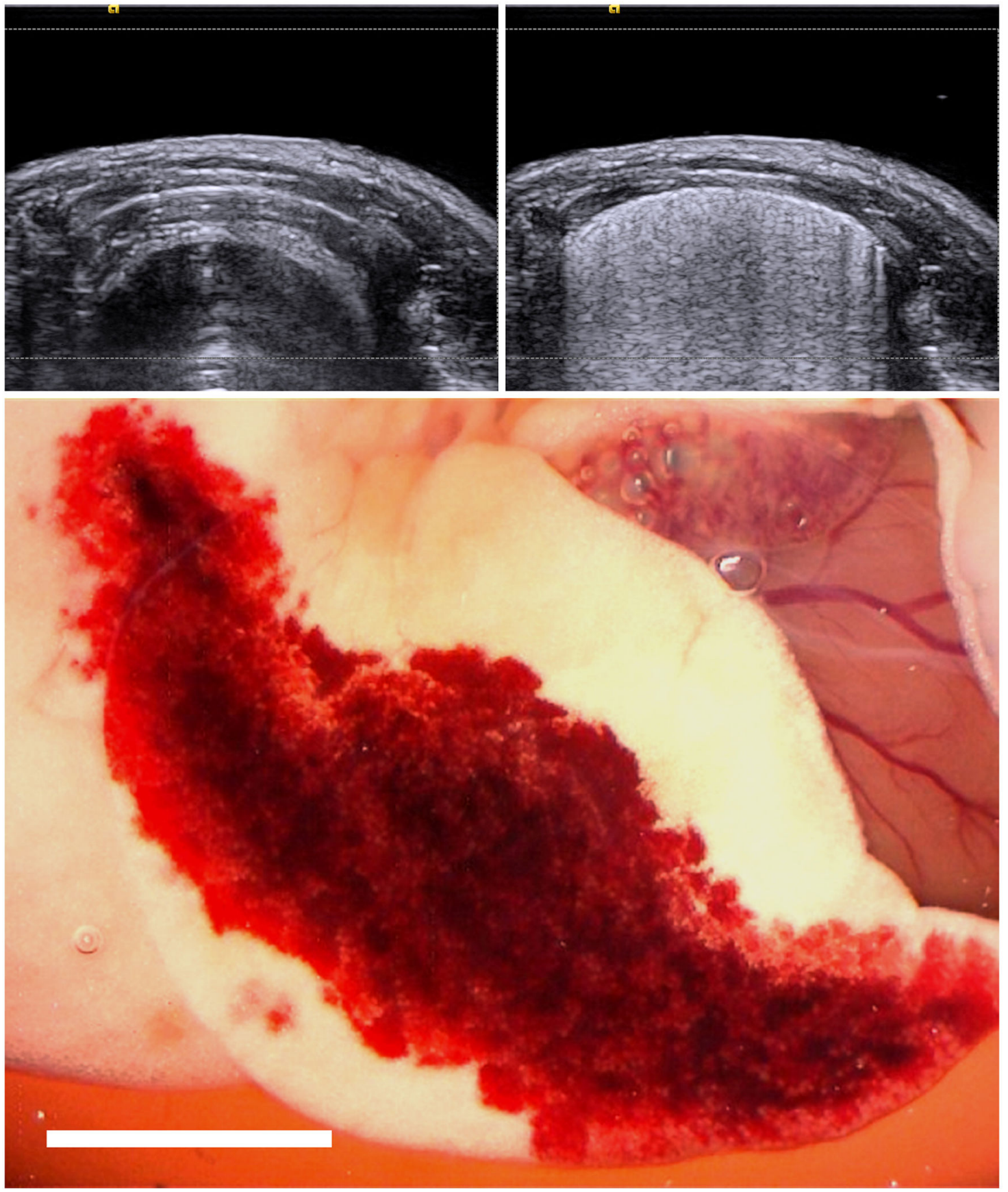

Figure 4.

B mode images were acquired just before (upper left) and 5 min after (upper right) 20 ARFI elastography frames with IPPV, presented as in Fig. 2. The after-exposure image displays comet-tail artifacts spread across the lung surface image. Substantial pulmonary capillary hemorrhage ( $\mathrm{PCH}$ ) areas were produced on the medial lobe (bottom, scale bar $5 \mathrm{~mm}$ ), and other $\mathrm{PCH}$ areas were found on the cranial and caudal lobes. 

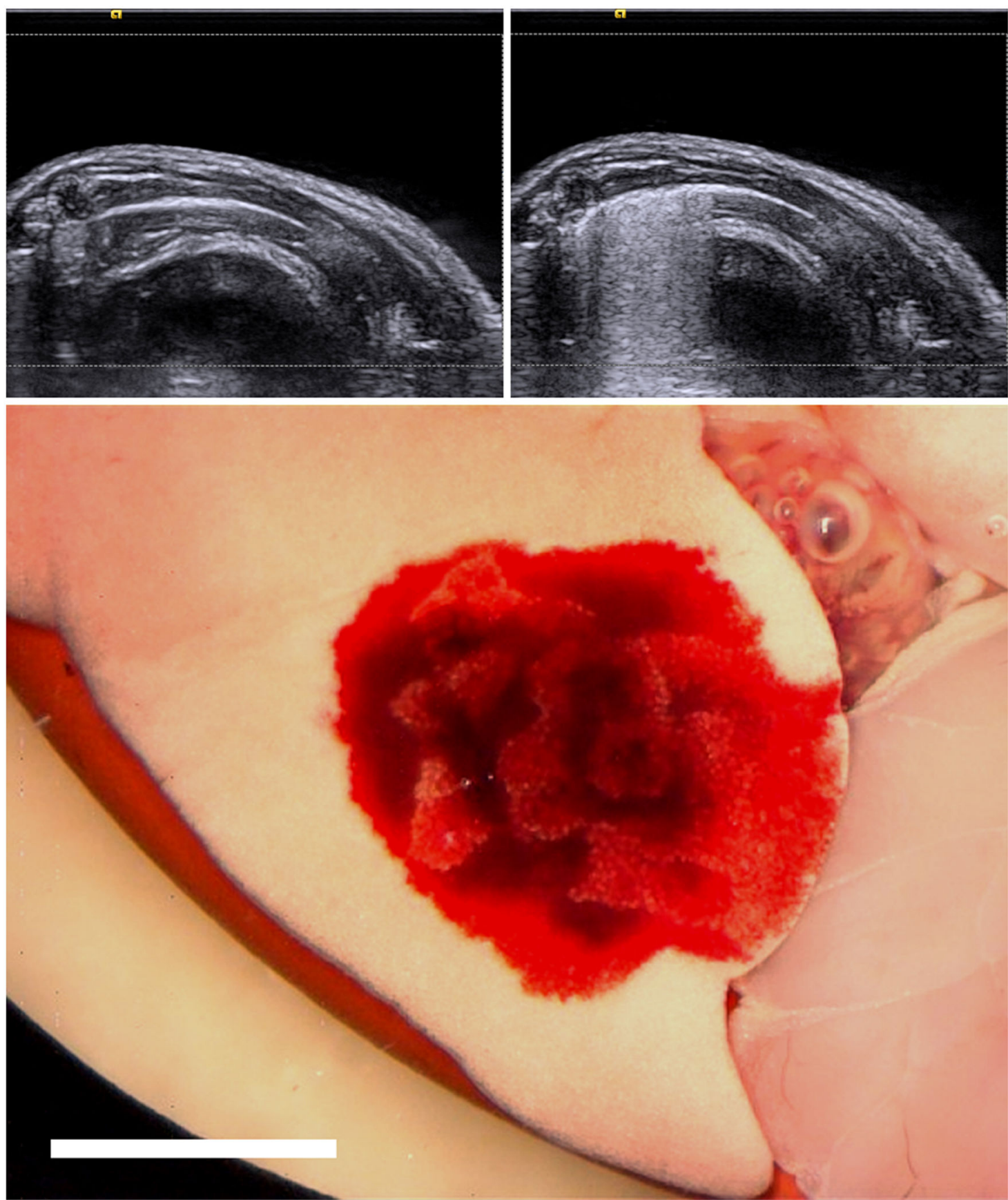

Figure 5.

Elastography maps acquired at the first (upper) and last (lower) ARFI elastography frames which were obtained during the same exposures as the results in Fig. 4. There was no apparent change in the elastography maps due to the exposure. The color map scale included shear wave velocities of $0.5 \mathrm{~m} / \mathrm{s}$ (blue) to $6.5 \mathrm{~m} / \mathrm{s}$ (red), with some yellow to red areas corresponding to the posterior position of rib and spine structures. 

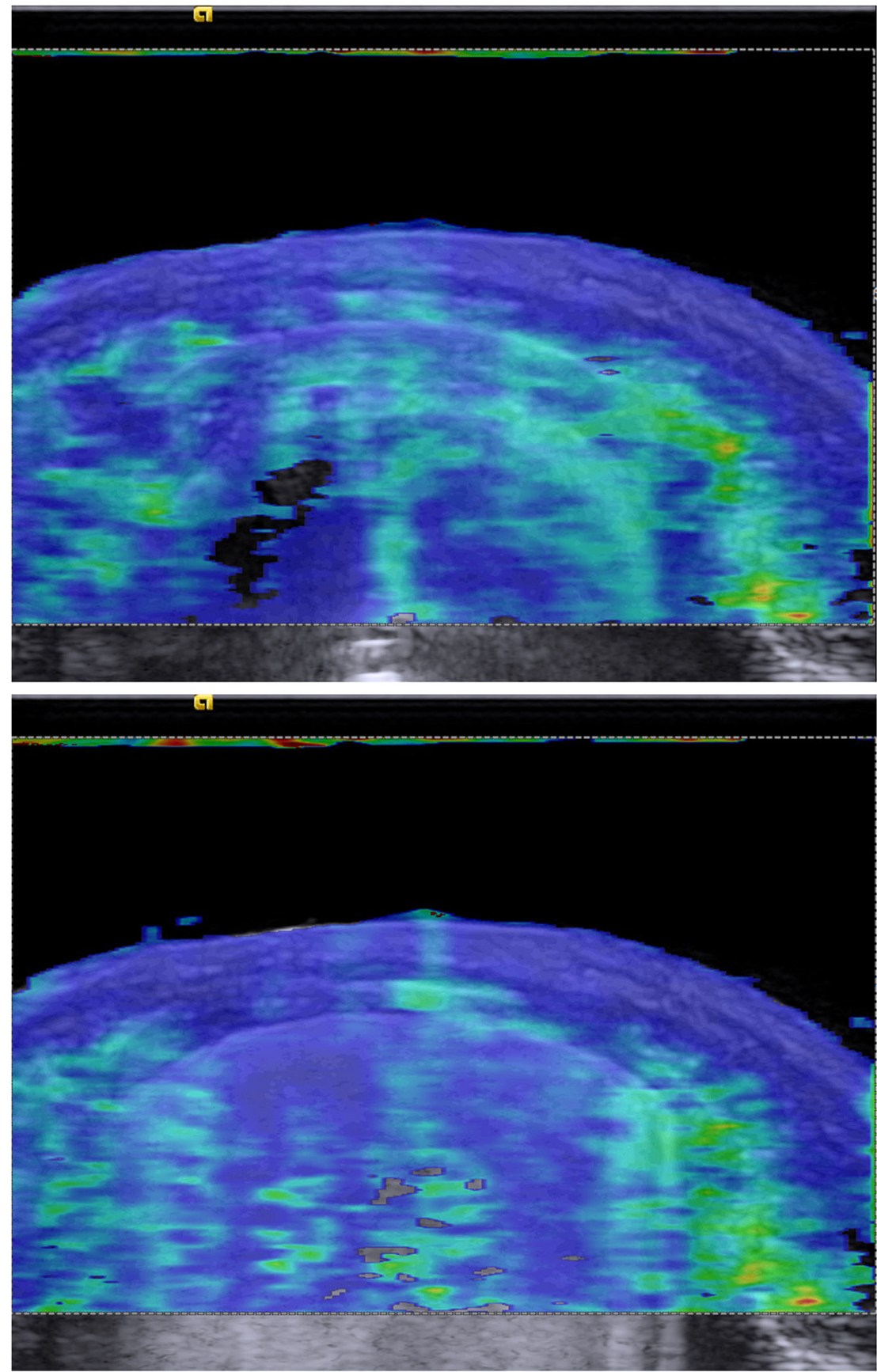

Figure 6.

$\mathrm{B}$ mode images acquired for each of the 20 ARFI elastography frames presented in in rows (i. e. frames 1 to 4 in the top row, etc.) The images show the progressive accumulation of comet tail artifacts across the bright-line lung surface image between the pre- and postexposure B mode images shown in Fig. 4 . 

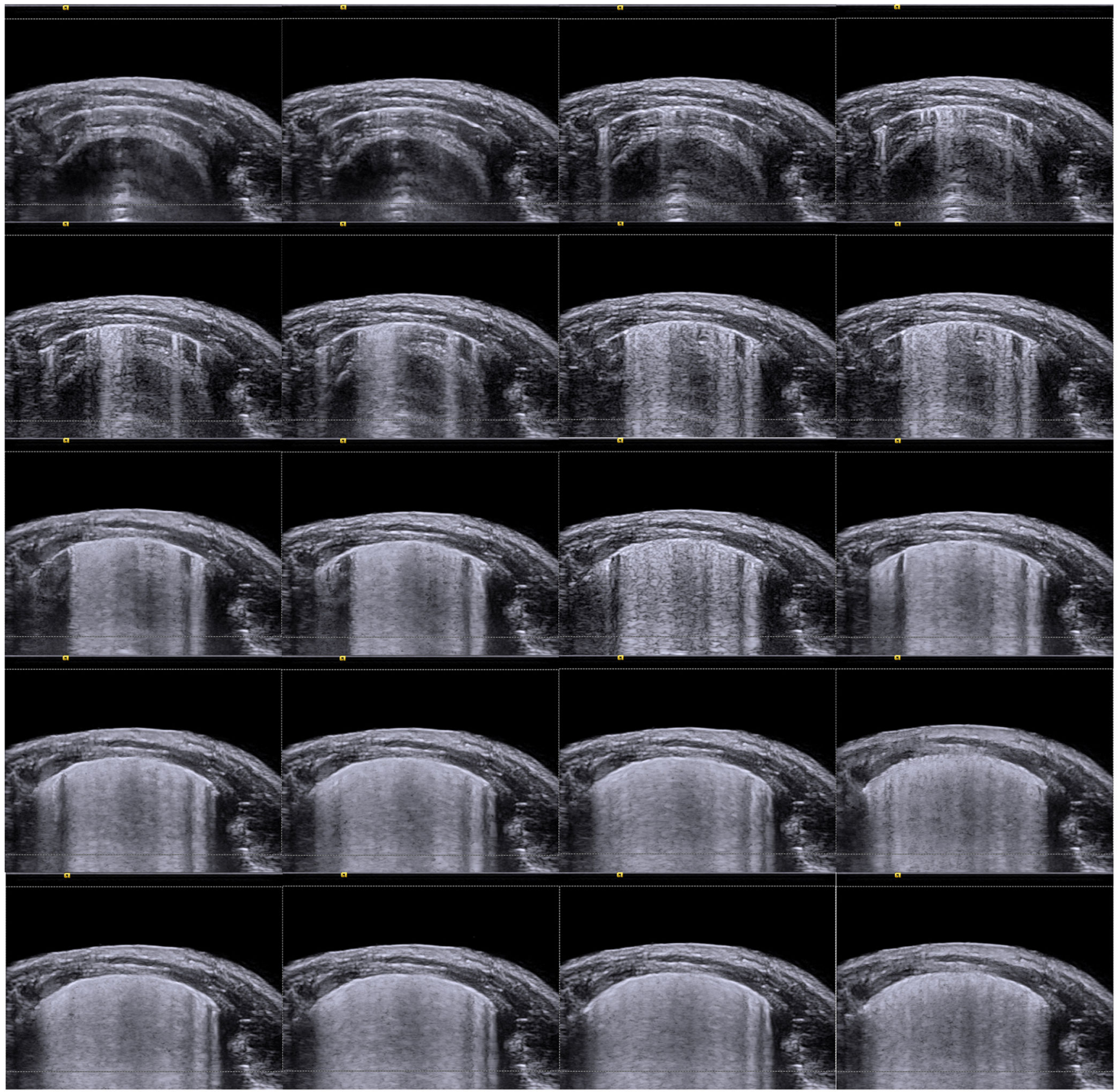

Figure 7.

B mode images were acquired just before (upper left) and 5 min after (upper right) 20 ARFI elastography frames with IPPV plus PEEP, presented as in Fig. 2. The after exposure image displays comet-tail artifacts spread across about half of the lung surface image. Substantial pulmonary capillary hemorrhage areas were produced on the medial lobe (bottom, scale bar $5 \mathrm{~mm}$ ), and another PCH area was found on the cranial lobe. 


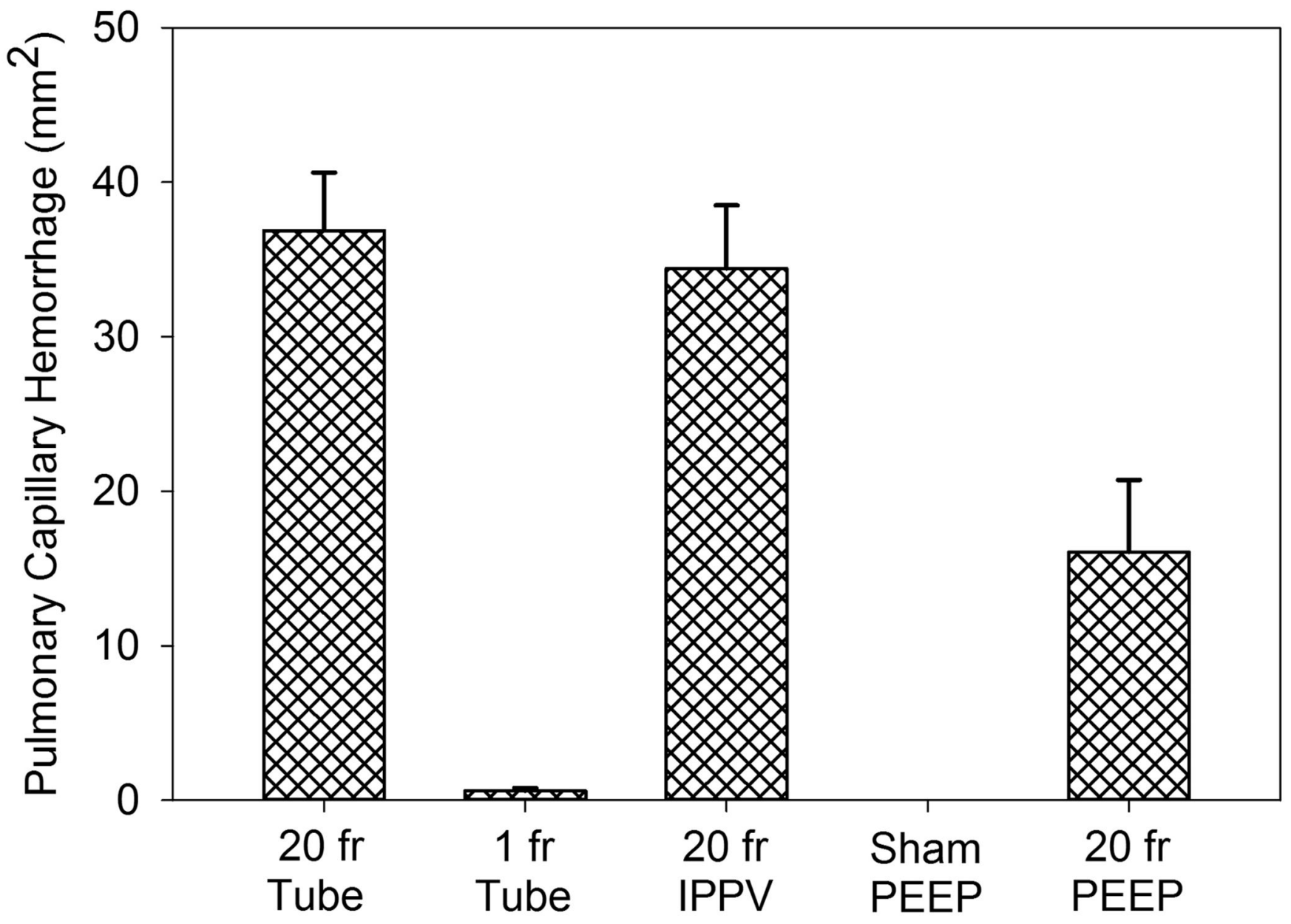

Figure 8.

Results for the pulmonary capillary hemorrhage ( $\mathrm{PCH}$ ) areas for the 5 different conditions listed in Table 1. All exposure conditions were significantly greater than the sham condition, for which no PCH was seen. For the tracheal tube only with spontaneous breathing (Tube) the result for 1 frame was significantly less than the result for 20 frames $(\mathrm{p}=0.015)$. The addition of PEEP to the IPPV significantly reduced the PCH $(\mathrm{p}<0.001)$. 
Table 1.

Pulmonary capillary hemorrhage results for diagnostic ultrasound scanning in the ARFI Virtual Touch IQ elastography mode: CTA \%, the percentage of CTAs in the lung surface image. The 1 frame with tube only (spontaneous breathing) was significantly less than the 20 frame exposure $(\mathrm{p}=0.002)$. and the IPPV + PEEP was significantly less than IPPV ( $\mathrm{p}=0.014)$. The volume of $\mathrm{PCH}$ was estimated for the higher impact conditions.

\begin{tabular}{cccccccc}
\hline Condition & $\mathbf{N}$ & Exposure frames & CTA \% & PCH Proportion & Area mm $\mathbf{~}^{2}$ & Significance p & Volume $\boldsymbol{\mu L}$ \\
\hline Tube only & 6 & 20 & $97 \pm 5$ & $6 / 6$ & $36.9 \pm 9.2$ & 0.002 & $97.3 \pm 44.9$ \\
Tube only & 6 & 1 & $6 \pm 5$ & $5 / 6$ & $0.61 \pm 4.5$ & 0.015 & - \\
IPPV & 6 & 20 & $90 \pm 19$ & $6 / 6$ & $34.4 \pm 10.0$ & 0.002 & $80.6 \pm 31.1$ \\
IPPV+PEEP & 6 & 0 & 0 & $0 / 6$ & 0 & - & - \\
IPPV+PEEP & 7 & 20 & $56 \pm 31$ & $7 / 7$ & $13.1 \pm 12.3$ & 0.001 & $35.3 \pm 34.2$ \\
\hline
\end{tabular}

